\title{
A Proposal for Improving Forward Guidance
}

\author{
Leo Krippner, Senior Adviser, Reserve Bank of New Zealand \\ Daniel T. Thornton, Vice President and Economic Adviser
}

I n December 2008 the Federal Open Market Committee (FOMC) reduced its target for the federal funds rate to effectively zero and announced that weak economic conditions were likely to keep the funds rate "exceptionally low" for an "extended period." This statement was widely interpreted as providing the market with forward guidance on the future path of the policy rate in order to reduce longer-term yields by more than a zero policy rate alone. The efficacy of forward guidance depends critically on the credibility of the FOMC's commitment to keep the policy rate low-the more credible the commitment, the larger the effect on long-term yields. This essay briefly introduces issues relevant to the efficacy of the FOMC's forward guidance policy and proposes a simple method for increasing that efficacy at the zero lower bound.

The FOMC has used two approaches to enhance the efficacy of its forward guidance policy: making large-scale asset purchases (LSAPs) of longer-term debt and indicating a conditional commitment to keep the policy rate exceptionally low until a particular future date. The potential of Fed LSAPs to enhance the efficacy of its forward guidance policy was noted by Narayana Kocherlakota, president of the Federal Reserve Bank of Minneapolis. ${ }^{1}$ The essential idea is that if the federal funds rate were to rise faster than the FOMC's forward guidance would seem to suggest, then the Fed would incur a greater capital loss on its holdings of longer-term debt than if there were more moderate fund rate increases.

Regarding conditional commitment, the announcement of a particular future date should reduce market uncertainty about the likely duration of exceptionally low interest rates. The first such announcement was made on August 9, 2011, when the FOMC indicated that it expected the policy rate to be exceptionally low "at least through mid-2013." On January 25, 2012, the Committee extended the date to "at least through late 2014," and on September 13, 2012, to "at least through mid-2015." Despite the FOMC's use of specific dates, some analysts have suggested that the FOMC's forward guidance policy has so far been relatively unsuccessful and attribute the lack of success to a lack of credibility of the commitment. ${ }^{2}$

Our proposal for improving the credibility of the FOMC's forward guidance combines an announced period of a (near) zero federal funds rate with large-scale purchases of interest-rate-derivative contracts customized for that period. For clarity, we illustrate the idea with an example based on exchange-traded 3-month overnight indexed swap (OIS) contracts for a single expiry date, although other interest rate derivatives and a variety of contract expiry dates over the guidance period would likely prove a more pragmatic choice in practice. ${ }^{3}$

\section{Our approach offers several advantages over LSAPs as a financial mechanism to enhance forward guidance.}

If the FOMC wanted to make a firm commitment to keep the policy rate near zero until at least mid-2015, it could purchase, say, 500,000 OIS contracts that expire in June 2015 at a zero fixed rate. As long as the FOMC keeps the funds rate near zero, the contracts will expire with no financial loss. But if the FOMC decided to increase the funds rate to, say, 1 percent before December 2014, it could lose as much $\$ 1.25$ billion (500,000 contracts $\times \$ 25$ per basis point per contract $\times 100$ basis points). In general, the Fed would incur a loss proportional to the difference between the actual federal funds rate and the near-zero forward guidance rate. Note that the Fed could not decrease the funds rate to impose losses on the issuers of OIS contracts because of the zero lower bound, so market participants should be readily prepared to enter into an arrangement that will return to them either nothing (if the FOMC delivers its period of near-zero policy as per its guidance) or a positive payoff (if the FOMC reneges).

Making such a financial commitment with OIS contracts would enhance the credibility of the FOMC's forward 
guidance commitment assuming, naturally, that the market believes the Fed wishes to avoid or limit such losses. Indeed, the market could readily evaluate the strength of the FOMC's commitment by the notional value of the Fed's portfolio of OIS contracts. The larger the derivative position, the larger the contingent loss relative to the Fed's capital plus expected seigniorage income, and therefore the more credible the commitment.

Our approach offers several advantages over LSAPs as a financial mechanism to enhance forward guidance. First, contracts can be obtained for precise time horizons and in the exact volumes desired to maximize the degree of the FOMC's commitment. Second, the approach is very transparent: The Fed could publish the volume of the sequence of its contracts daily, so the market would always know the Fed's exposure to potential financial loss should the Committee renege on its commitment. Conversely, the potential loss associated with LSAPs is not as transparent. In principle, by using the size and average duration (a measure of the price sensitivity of the portfolio to changes in the interest rate) of the Fed's portfolio, markets could estimate the Fed's potential capital loss should it renege on its commitment. However, the true loss would depend on the distribution of the portfolio by maturity because interest rates of different maturities have varying sensitivities to changes in the funds rate. ${ }^{4}$ In addition, for any given portfolio, the loss could be influenced by the exact path of the funds rate increase-the slower the increase, the smaller the loss.

Third, avoiding losses via portfolio adjustments would be nearly impossible under our proposal. Under the current procedure the Fed could reduce its loss, perhaps very significantly, by selling longer-term securities in advance. It is even conceivable that the FOMC could renege on its commitment without suffering a significant capital loss. With our proposal, if the Fed attempted to limit its loss by selling the contracts in advance, the market would realize that the FOMC was preparing to renege on its commitment and the value of the contract would fall with the Fed's selling pressure and the market's anticipation of the likely level of the federal funds rates at the contract expiry. Hence, the Fed would likely incur a capital loss of a similar order of magnitude relative to holding the contracts to maturity.
Fourth, unlike LSAPs, the purchase of derivatives has no effect on the Fed's balance sheet. Hence, there is no perceived inflation potential, as there is with LSAPs. Fifth, the commitment is explicitly targeted at the federal funds rate; all other rates in the economy remain free from direct Fed intervention. With regard to the latter point, the Fed's holding of U.S. Treasury securities would no longer potentially distort the secondary and repurchase markets, as recent market dynamics have suggested. Sixth, exiting the policy is simple: The contracts are simply allowed to expire. Consequently, there are no market distortions that might result from selling large quantities of debt when the extraordinary monetary accommodation period is due to end.

\footnotetext{
Notes

${ }^{1}$ Kocherlakota, Narayana. "The Tools of the FOMC." Speech presented in Fargo, North Dakota, on October 19, 2010. Note also that this credibility effect would be in addition to the often-cited portfolio balance channel for LSAPs, but we do not discuss the latter here.

${ }^{2}$ For example, see Woodford, Michael. "Methods of Policy Accommodation at the Interest Rate Lower Bound." Presented at a symposium sponsored by the Federal Reserve Bank of Kansas City, "The Changing Policy Landscape," Jackson Hole, Wyoming, August 31, 2012,

http://kansascityfed.org/publicat/sympos/2012/mw.pdf; and Thornton, Daniel L. "Verbal Guidance and the Efficacy of Forward Guidance." Federal Reserve Bank of St. Louis Economic Synopses, 2012, No. 26, September 28, 2012.

${ }^{3}$ An OIS contract is an agreement to exchange the future realized federal funds rate versus the fixed rate traded on the exchange, where both rates apply to a preagreed-upon notional principal amount of $\$ 1$ million; for the full specifications, see the CME Group's website (www.cmegroup.com/trading/interest-rates/stir/3month-ois_contract_specifications). However, OIS contracts do not presently command large volumes, so over-the-counter OISs (either forward-starting or outright) would be more suitable because (i) they have outstanding volumes of several trillions of dollars of face-value equivalence (see, for example, Fleming, Michael; Jackson, John; Li, Ada; Sarkar, Asani and Zobel, Patricia. "An Analysis of OTC Interest Rate Derivatives Transactions: Implications for Public Reporting." Federal Reserve Bank of New York Staff Report No. 557, March 2012; www.newyorkfed.org/research/staff_reports/sr557.pdf) and (ii) they can be transacted directly with counterparties (rather than by an exchange), which allows them to be highly customized with precise dates and volumes. Over-thecounter interest rate swaps and exchange eurodollar futures are also heavily traded markets that could be used for our proposal, given appropriate adjustments relative to OIS rates.

${ }^{4}$ For example, 3-month interest rates will shift almost identically with the funds rate, but the change in the 10-year Treasury yield could range between zero and about 25 basis points per 100-basis-point change in the funds rate. See Thornton, Daniel L. "Monetary Policy at the Zero Bound." Federal Reserve Bank of St. Louis Economic Synopses, 2011, No. 7, February 25, 2011; http://research.stlouisfed.org/publications/es/11/ES1107.pdf.
} 